\title{
Achieving PAP-DIB Objective Capabilities by Transforming the Way We Think
}

Scott E. Jasper *

You can bring all the new technologies you want, but if you don't change how you think, you will not achieve transformation.

- United States Air Force Maj. Gen. Marc Rogers ${ }^{1}$

The transformational model is one in which lessons learned, innovative thinking, education, and material implementation combine to promote capability improvement.

- Belgian Army Maj. Gen. Frank Hye ${ }^{2}$

The terrorist attacks on New York City and Washington, D.C. on September 11, 2001 graphically illustrated the unprecedented changes taking place in today's global security landscape. Throughout the world, but particularly in North America and Europe, nations were suddenly forced to confront the very real possibility of a devastating domestic attack by a dangerous and unpredictable enemy. In Europe, the situation rapidly evolved from potential threat to deadly crisis, as Madrid was rocked by a series of horrific train bombings in March 2004 and London's commuter transportation network was disrupted for weeks by Islamic extremist bomb attacks in July 2005. It soon became very clear that European security strategies geared towards traditional collective territorial defense did not provide the capabilities needed to address emerging global security threats. If there were any doubts beforehand, it was clear following these de-

Scott Jasper, CAPT, USN (Retired) serves as Chief Operating Officer and Lecturer in the Center for Civil-Military Relations at the Naval Postgraduate School. A graduate of the United States Naval Academy, he also holds Masters Degrees from San Jose State University and the United States Naval War College. Scott designed and now delivers practical exercise driven resident and mobile seminars on International Defence Transformation; more information at http://www.ccmr.org/public/spd.cfm/spi/idt.

1 Opening remarks at the Joint Warfare: Transformation and New Requirements conference in Arlington, VA, 22 June 2004. In 2003-04, Maj. Gen. Rogers led U.S. Joint Forces Command's J8 Directorate, which is responsible for integrating U.S. national military strategy with the U.S. Department of Defense's planning programming and budgeting system. The J8 reviews future capabilities requirements identified by field commanders, ensures joint and multi-national interoperability, and validates prototypes through experimentation and demonstration.

2 Excerpt from speech entitled "Demystifying Transformation," delivered at the Clingendael Security and Conflict Program in Kijkduin, the Netherlands, 14 December 2005. Major General Hye currently serves as the Supreme Allied Commander Transformation Representative in Europe. 
velopments that the status quo approach to NATO heartland security had lost its relevance. The Euro-Atlantic defense community was faced with two choices: to change or to transform. At the Istanbul Summit in 2004, Allies and Partners launched the Partnership Action Plan for Defense Institution Building (PAP-DIB), which established unified objectives for defense reform and capabilities development for collective security. ${ }^{3}$ The achievement of PAP-DIB objective capabilities requires a transformation mindset that thinks in new ways about how to address future security risks.

\title{
Transformation Defined
}

On the surface, transformation may seem synonymous with change, but there is a significant difference in perspective. Change is based on past events; it is a comparison or response to conditions that have already occurred. Transformation, on the other hand, indicates a more creative, forward-looking process that strives to anticipate the future and create capabilities that will address future conditions. ${ }^{4}$ Transformation embraces more than just the exploitation of new technologies, however; it also encourages changes in core concepts, processes, personal perceptions, and organizational structures. ${ }^{5}$ By definition, transformation has no end state. Rather, it is a continuing process that "encompasses accelerated technological modernization, doctrinal reform, re-orientation and re-organization of force structures, a culture open to change, and a willingness to accept risk."

\section{Developing Capabilities: Closing the Gap}

We want to develop the new military capabilities that NATO needs to fight the new threats we are facing today...

\author{
- A. Elizabeth Jones, Assistant Secretary \\ for European and Eurasian Affairs ${ }^{7}$
}

3 Partnership Action Plan on Defense Institution Building, Brussels, 7 June 2004; available in the NATO Online Library, at www.nato.int/docu/basictxt/b040607e.htm.

4 The importance of future-focused transformation is highlighted in Maj. Gen. Hye's presentation, "Demystifying Transformation," 2.

5 This definition incorporates the principle capability categories-Technology, Organizations, People, and Processes (TOPP) — as identified in the United States Office of Force Transformation's Military Transformation: A Strategic Approach (Washington, D.C., 2003), 10; available at www.oft.osd.mil/library/library_files/document_297_MT_StrategyDoc1.pdf.

6 General Lance L. Smith, "Understanding NATO Military Transformation" (ACT Multimedia Library, Norfolk, VA, 2006), 4. See www.act.nato.int/multimedia/facts/UNMT\%20 Booklet $\% 20$ English\%20Version.pdf.

7 A. Elizabeth Jones, “The Road to NATO's Prague Summit: New Capabilities, New Members, New Relationships," a speech to the World Affairs Council of Northern California (San Francisco, 21 October 2002). 
The Prague Summit of November 2002 defined and unified NATO's transformation efforts after 9/11. Widely acclaimed as a "Transformation Summit," lined an Alliance command structure previously suited for the Cold War ${ }^{9}$ and heralded the birth of Allied Command Transformation, the lead agency in "...promot[ing] the transformation of Alliance militaries and improv[ing] their ability to inter-operate, whilst enhancing the transatlantic link." ${ }^{10}$ Prague also defined new capabilities for future forces, as manifested in the Prague Capabilities Commitment. The Prague Capabilities Commitment challenged individual nations to make specific commitments to improve collective capabilities in eight priority fields where gaps were identified:

- Chemical, biological, radiological, and nuclear (CBRN) defense

- Intelligence, surveillance, and target acquisition

- Air-to-ground surveillance

- Command, control, and communications

- Combat effectiveness (including precision-guided munitions and suppression of enemy air defenses)

- Strategic air and sea lift

- Air-to-air refueling

- Deployable combat support and combat service support units. ${ }^{11}$

It soon became apparent that these capability gaps could not be fully addressed within the Alliance - a wider response was needed. ${ }^{12}$ NATO expanded its capabilities development efforts to include Partner nations that possessed the ambition to participate, adequate resources, and, most importantly, a democratically controlled defense infrastructure. The Partnership Action Plan on Defense Institution Building (PAP-DIB) was developed as a tool "to promote democratic values and foster democratic transformation across the Euro-Atlantic area, providing interested Partners with political

8 Former NATO Secretary-General Lord George Robertson, in discussion with U.S. President George W. Bush in October 2002, remarked that the NATO summit in Prague "will be a transformation summit where the alliance must transform itself to deal with the threats and the challenges of the 21 st century." (Washington, D.C., 2002), www.defenselink.mil/news/ Oct2002/n10212002_200210218.html.

9 See John Borawski and Thomas-Durell Young, NATO after 2000: The Future of the EuroAtlantic Alliance (Westport, CT: Praeger, 2001), passim.

10 NATO's Command Structure: The Old and the New (June 2004); available at www.nato.int/ims/docu/command-structure.htm.

11 NATO Informational flyer, "NATO After Prague: New Members, New Capabilities, New Relations" (Brussels: NATO, 2004), 2-3.

12 German Federal Minister of Defense, His Excellency Dr. Peter Struck, MdB, made this point amply clear in his keynote address to the $21^{\text {st }}$ International Workshop on Global Security. Dr. Struck examined today's global security environment and expressed the need for a unified response: "The Western world will not be able to control this threat by going it alone." (Berlin, May 2004); available at www.csdr.org/2004book/PeterStruckKeynote.htm. 
and practical advice on, and assistance in, the defense and security-related aspects of the domestic reform [process], including [bringing] armed forces under civilian and democratic control.",13

The PAP-DIB provides a conceptual framework for multilateral cooperation in defense reform. ${ }^{14}$ PAP-DIB uses existing PfP instruments, such as the Individual Partner Action Plan (IPAP) and Membership Action Plan (MAP) to pursue PAP-DIB objectives. The specific PAP-DIB objective that engages Partner nations in NATO defense transformation initiatives is Objective 5.4: "Develop effective and transparent arrangements and procedures to assess security risks and national defense requirements; develop and maintain affordable and inter-operable capabilities corresponding to these requirements and international commitments, including those within the framework of PfP." $" 15$

\section{The Importance of Education}

The biggest challenge, perhaps, takes place in the minds of peopleintellectually and culturally.

- General Lance Smith, Supreme Allied Commander Transformation ${ }^{16}$

Transformation demands institutional ambition. Technology is the easy part; the more important - and more challenging — capabilities to develop are "cognitive capabilities." Cognitive capabilities are developed by establishing a fundamental understanding of transformational concepts and a culture willing to embrace innovation. In effect, education is the key enabler for creating a transformational mindset.

This mindset is reflected in the Euro-Atlantic Partnership Council's (EAPC) recognition that meeting tomorrow's challenges rests upon the ability of the Alliance to transform in order to prevail in the complex future security environment. ${ }^{17}$ PfP nations and multi-national partners supporting NATO security objectives need to achieve interoperability with NATO member forces to work seamlessly together. Future military

13 NATO, EAPC(C)D(2006)0011: "Implementing the PAP-DIB: The Education and Training for Defense Reform Initiative - Guidelines for Development," 23 February 2006.

14 PAP-DIB places military transformation in the context of the military's security role in civil society and the involvement of the military in non-traditional stability and peacekeeping roles. Dr. Karen Guttieri's essay, "Professional Military Education in Democracies," in Soldiers and Statesmen: Institutional Bases of Democratic Civilian Control (Austin: University of Texas Press, 2006), 318-320, explores this evolution in detail.

Partnership Action Plan on Defense Institution Building, Brussels, 7 June 2004.

16 General Lance L. Smith made this remark in his brief "NATO Military Transformation" on 16 March 2006 at the PfP Transformation Conference in Skopje, Former Yugoslav Republic of Macedonia.

17 Gen. James L. Jones and Adm. Edmund P. Giambastiani, Jr., "Strategic Vision: The Military Challenge," Allied Command Transformation (Norfolk, VA: ACT Multimedia Library, August 2004), 2. See www.act.nato.int/organization/transformation/docs/stratvis0804.pdf. 
forces need to be agile, joint, and expeditionary in nature, and must be designed to contribute effectively in operations across the spectrum of conflict. Defense transformation is seen by the Alliance and other concerned nations as the catalyst that is needed to achieve preeminence in warfare and crisis resolution in the Euro-Atlantic region and beyond.

To date, however, the insights gained in transformation workshops and the practical experiences gained from participation in multi-lateral missions have provided only limited opportunities for aspirant nations to acquire the knowledge and practical skills needed to design and implement plans for defense transformation. Nations facing the diverse security challenges of the new century deserve academic programs that will foster greater understanding on how to best optimize their national transformation agendas.

Building an experienced and educated transformation cadre is a difficult challenge common to militaries worldwide. Well-educated, trained, and experienced military planners are high in demand. Staff officers generally face each new assignment with little or no formal training or mentorship. Few defense organizations can afford to spare critical staff for several months of academic training, and must often resort to ad hoc, learning-on-the-job approaches that result in costly and preventable errors, misunderstandings, or inefficient use of time and resources.

To help in addressing these shortfalls, Allied Command Transformation and the United States Joint Forces Command, working in partnership with the Naval Postgraduate School, the United States' PfP Training and Education Center, ${ }^{18}$ and the United States Office of Force Transformation have developed short-duration, focused educational seminars in International Defense Transformation that explore transformation principles, methodologies, and practical applications. ${ }^{19}$ The ultimate goal is to build a core transformation community of interest, made up of international civilian and military defense planners and policy-makers who share a clearer understanding of what transformation means, why it is essential, and how to translate transformational concepts into operational capabilities that can be brought to bear to address current and future security concerns.

18 Jaap de Hoop Scheffer, NATO Secretary-General, stated: "the addition of the U.S. Postgraduate Naval School as a PfP Centre has significantly enhanced the contribution to education in support of PfP priorities agreed at the Istanbul Summit." Cover letter to the 2006 Annual Status Report of PfP Training Centers, dated 19 January 2006.

19 This partnership has culminated in an annual resident seminar, presented for the first time at the Naval Postgraduate School in December 2005. Participants included national representatives from Bulgaria, Latvia, Romania, Moldova, Chad, Indonesia, Nepal, Pakistan, and Trinidad and Tobago, as well as observers from the Geneva Centre for Security Policy, the NATO School, the NATO Defense College, and the Slovak Republic Military Academy. This group now forms the core membership of the fledgling Transformation Community of Interest, which regularly shares transformation news and events, enrichment modules, and exchange of ideas via a dynamic, web-based virtual network at www.ccmr.org/public/ spd.cfm/spi/idt. 
PAP-DIB underlines the importance of this common understanding of concepts and unity of effort as Partners endeavor to transform themselves by developing new capabilities and achieving the envisaged Military Tasks for Interoperability objectives of the forces that can be declared available for NATO-led PfP activities, including operations, as outlined in country-specific Partnership Goals. As participants in the PAPDIB process, "Allies and Partners commit themselves to engage in a dialogue, exchange of experience, and share practical cooperation." ${ }^{20}$ PAP-DIB codifies the vital role of education in the transformation process. In particular, it prescribes conferences, workshops, and mentoring initiatives as primary vehicles for fostering cooperation and dialogue between transformation theorists and scholars and the end-users in the military and defense communities. However, as previously argued, a simple exchange of ideas is not enough. These educational venues must bridge the gap between core concepts and practical approaches for capability development.

Achieving the objectives of PAP-DIB complements the PfP's Training and Education Enhancement Program (TEEP). TEEP is designed "to increase the capacity of training and education efforts to meet the current and future demands of the enhanced and more operational Partnership. ${ }^{21}$ TEEP calls for enhancing the number and quality of Partnership for Peace Training and Education Centers to promote inclusive training and education "available to all Allies and Partners.",22 TEEP has targeted interoperability and improved access to educational opportunities for Partners as two of its primary objectives. The aim of improving NATO/PfP interoperability is showcased in PfP participation in NATO operations in Kosovo, Bosnia-Herzegovina, Afghanistan, and NATO-sanctioned training missions in Iraq. ${ }^{23}$

\section{Capability Development Process: A Coherent Approach}

Within the Capabilities Management Framework, ${ }^{24}$ ACT developed a methodology for systematically transforming both NATO and Partner nations: the Capability Develop-

20 Istanbul Summit Reader's Guide "Partnership Action Plan on Defense Institution Building," (Brussels: NATO-OTAN 2004), 75-76.

21 Burak Akçapar, NATO's Defense Planning and Operations Division, "PfP Training Centres: Improving training and education in the Partnership for Peace," NATO Review 47:3 (Autumn 1999): 31-32.

22 "Report by the Political Military Steering Committee on PfP," Appendix E; available at www.nato.int/pfp/docu/d990615f.htm.

23 Jeffrey Simon, "Partnership for Peace: Charting a Course for a New Era," EJournal USA, U.S. Foreign Policy Agenda (June 2004); available at http://usinfo.state.gov/journals/itps/ 0604/ijpe/simon.htm. A few examples of varying levels of PfP participation in expeditionary campaigns include: Kyrgyzstan, Uzbekistan, and Ukraine (OEF); Albania, Finland, Sweden, and Austria (ISAF); Macedonia, Ukraine, Azerbaijan, Georgia, and Kazakhstan (OIF).

The final version of Annex A to ACT Directive 80-7 (Managing Transformation), "A Framework for ACT Capabilities Management Organization and Processes," was released on 20 April 2005. It provides guidance on management approaches, the development of the Integrated Capability Teams (ICTs), and the foundation for the Capabilities Development Process; see 4-17. 
ment Process (CDP). ACT visualizes it as a sort of transformation "highway-a well defined origin, destination, and route, but with several on and off ramps permitting free entrance and exit to the flow of ideas at all stages. ${ }^{~} 25$ The Capability Development Process is depicted below: ${ }^{26}$

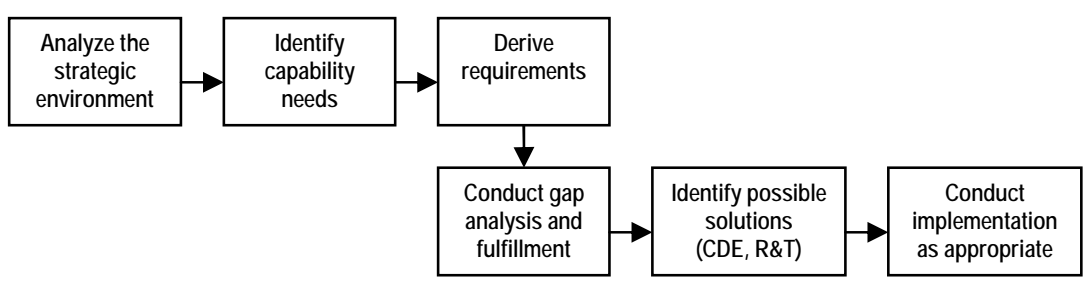

Figure 1: Capability Development Process

Capabilities development begins with an understanding of both the current and potential future security environment. Today, and for the foreseeable future, this environment is defined by the following global threats: organized crime, networked terrorism; rogue nations with capabilities and intent to impact the international community; proliferation of weapons of mass destruction; increased competition for scarce global resources; and a growing international demand for expeditionary peacekeeping and humanitarian aid/disaster relief missions in unstable regions. ${ }^{27}$

At the 2002 Prague Summit, NATO publicly recognized the need for sweeping changes in its missions, structure, and mindset. The uncertainties that have emerged from globalization now render traditional "territorial defense" mentalities obsolete. In consequence, the EAPC has moved away from a "threat-based" focus on traditional enemies and battlefronts, aligned along territorial borders, to a more flexible, generalized planning strategy that can be applied to a wide range of challenges - in short, capabilities-based planning. This dynamic conceptual shift was born of necessity. In the post-9/11 world, long-standing traditions of territorial defense, loosely allied militaries under sovereign national control, and a narrow focus on response to a land war in Europe are simply no longer relevant.

25 Remarks by then-Acting Supreme Allied Commander Transformation (ASACT), Admiral Sir Mark Stanhope, RN, KCB, OBE, during a visit with participants in the NATO Defense College's General and Flag Officers and Ambassadors Course, Brussels, October 2005.

26 Simplified diagram from ACT's Capabilities Management Framework (May 2005), 4. Many of the steps occur concurrently or non-sequentially in an interactive and non-linear process.

27

See address by Mr. J.P. Colston, Assistant Secretary-General for Defense Policy and Planning, at the PfP Transformation Conference in Skopje (16 March 2006): "We face an unpredictable security environment, characterized by instability resulting from ethnic and religious tensions, failed and failing states, organized crime, resource scarcity and political and economic rivalries." Available at www.act.nato.int/events/documents/pfp06/colston.pdf. 
In the words of Mr.J.P. Colston, Assistant Secretary-General for Defense Policy and Planning, "The risks we face today are not the risks of strategic attack; they are the risks associated with the proliferation of weapons of mass destruction and the terrorist threat." 28 These new threats require a global response that is "agile, joint, and expeditionary." 29 Moreover, "defending the heartland" has taken on a new and geopolitically significant meaning with the bold, first-time invocation of Article V of the North Atlantic Treaty as a justification for pre-emptive military action in the name of collective defense in the global war on terror. ${ }^{30}$

\section{A Vision for the Future}

We need forces that are slimmer, tougher, and faster; forces that can reach further, and stay in the field longer.

- NATO Secretary General Jaap de Hoop Scheffer ${ }^{31}$

These changes in mindset and approach are captured in Strategic Vision: The Military Challenge, a document issued by NATO in 2004. ${ }^{32}$ The Concepts for Alliance Future Joint Operations (CAFJO) translates NATO's Strategic Vision guidance into concepts and capabilities for conducting coalition operations over the next fifteen years. ${ }^{33}$ The CAFJO institutionalizes ACT's three primary transformation goals: achieving coherent effects, ability to conduct multi-national joint expeditionary operations and achieving decision superiority, which enable an effects-based approach to operations (the integration of all instruments of Alliance power to achieve the desired end state). To achieve these goals, ACT identifies six transformational objective areas:

- Effective engagement and joint maneuver

- Enhanced civil-military cooperation

- Projection of forces

- Synchronized multinational and joint logistics

28 Ibid.

29 NATO's Strategic Commanders, Strategic Vision: The Military Challenge (ACT Multimedia Library, Norfolk, VA, August 2004), 5; www.act.nato.int/organization/transformation/docs/ stratvis0804.pdf.

30 Joseph R. Biden, Jr., U.S. Senator from Delaware and Ranking Democrat Member of the Senate Committee on Foreign Relations, "The Istanbul Summit: Stepping Up To The Challenge," EJournal USA (June 2004); available at http://usinfo.state.gov/journals/itps/0604/ ijpe/biden.htm.

31 Speech by NATO Secretary-General Scheffer at the Royal United Services Institute, London (18 June 2004); available at www.nato.int/docu/speech/2004/s040618a.htm. Accessible online at www.act.nato.int/organization/transformation/docs/stratvis0804.pdf.

33 "Concepts for Alliance Future Joint Operations," 20 February 2006. (Limited-distribution document available at the International Defense Transformation Blackboard Community page. For access, please contact the Center for Civil-Military Relations, www.ccmr.org/ public/spd.cfm/spi/idt.) 
- Information superiority

- Network-enabled concept

This progression is visualized in the diagram below: ${ }^{34}$

CAFJO paves the way for the introduction of an effects-based approach to operations, provides a relevant context for Alliance transformation, and establishes the parameters for integrating concept development and experimentation into the Capabilities Management Framework. The CAFJO creates a parallel structure to the Capstone Concept for Joint Operations (CCJO), the U.S. vision of the future joint force. The CCJO summarizes the family of joint operations concepts (JOpsC) that describe how joint forces are expected to operate across the spectrum of conflict from 2012 through $2025 .^{35}$

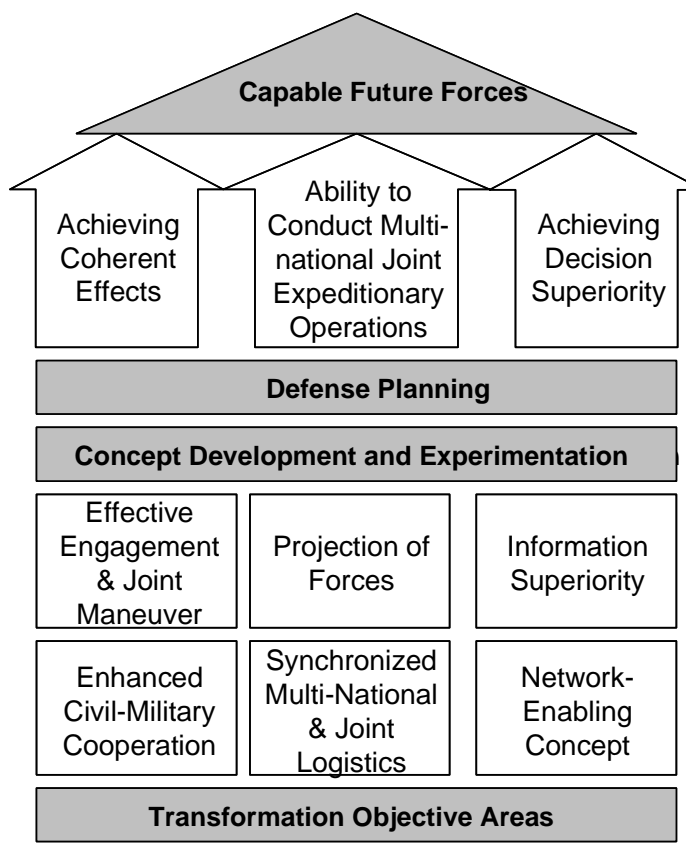

Figure 2: Effects-Based Approach to Operations

34 "House of Transformation" diagram from Maj. Gen. Hye, "Demystifying Transformation," 5 (edited to reflect most current CAFJO terminology per HQ SACT 5000TC-50/Ser: NU0040 of 20 February 2006).

35 The CAFJO, in some ways, is NATO's commitment to the CCJO vision for multinational integration in future operations. See U.S. Department of Defense, "Capstone Concept for Joint Operations," version 2.0 (2005), 2, http://www.dtic.mil/futurejointwarfare/concepts/ approved_ccjov2.pdf. 
The CCJO delineates the key characteristics of joint forces: knowledge-empowered, networked, interoperable, expeditionary, adaptable/tailorable, enduring, precise, fast, resilient, agile, and lethal. The CAFJO offers comparable characteristics: agile, joint, expeditionary, interoperable, networked, collaborative, effects-based, and interdependent. ${ }^{36}$ These key similarities will encourage the development of joint force characteristics for future U.S. and EAPC forces that are interoperable and compatible in scope and purpose.

\section{Changing Perceptions: NATO’s Evolving Role}

NATO's philosophy and approach have dramatically transformed and matured since the end of the Cold War. Until recently, however, the Alliance and its Partners have faced numerous challenges in realizing their ambitious goals. Part of the reason for this cultural resistance to the development of necessary operational capabilities has been a persistent mistrust among member nations about the European transformation agenda. In a recent NATO Review article, Mark Joyce noted that, "For skeptics, transformation became synonymous with a capital-intensive, network-centric, highly expensive and essentially U.S. model of military reform, to which it was unrealistic and undesirable for them to aspire." ${ }^{37}$ Additionally, many EAPC members have global aspirations that may not match their current capabilities. As General James Jones, the current Combatant Commander Europe and NATO Supreme Allied Commander acknowledges: "Unfortunately, NATO's political appetite to be global is much greater than its inherent capability to act globally.",38

NATO has taken significant action to develop capabilities that enable aspirations abroad while remaining cognizant of the political and economic limitations of its member and partner states. More and more often, "NATO is where [the world's] political leaders turn when they want to get something done." 39 In 2005, for example, NATO conducted eight simultaneous operations in theaters ranging from Pakistan to Louisiana.

\section{The Alliance Abroad: Building Force Projection Capabilities}

One indicator of the Alliance's commitment to building a viable expeditionary force is NATO and Partner involvement in the International Security Assistance Force (ISAF)

36 "Concepts for Alliance Future Joint Operations," 20 February 2006.

37 Mark Joyce defends Jaap De Hoop Scheffer's transformation efforts against these and other criticisms in "Taking the Transformation Agenda Forward," NATO Review (Spring 2005); available at www.nato.int/docu/review/2005/issue1/english/art5.htm. Mr. Joyce is head of the Transatlantic Program at the Royal United Services Institute, London.

38 Jane's Defense Weekly (January 2006), 34; available at http://down.nmag.cn/other/ Janes.Defense.Weekly.Magazine.January.25.2006.pdf.

39 The U.S. Principal Deputy Assistant Secretary of State for European and Eurasian Affairs, Mr. Kurt Volker, made this plain-spoken assertion to students at the Naval Postgraduate School and later to students and faculty the University of San Francisco in March 2006 in his lecture, "U.S. Foreign Policy and Europe" (Monterey, 2006). 
in Afghanistan. ${ }^{40}$ At the beginning of combat operations in 2002, Allies and Partners only fielded limited support to U.S.-led combat operations. In the last two years, however, NATO has rapidly ascended to assuming the lead role in establishing lasting stability in Afghanistan. As NATO took operational control in August 2003, Allies and coalition partners were creatively woven into the force structure through the implementation of a CIMIC-based, modular expeditionary prototype, the provincial reconstruction team.

A provincial reconstruction team (PRT) is a modular organization of roughly forty to one hundred civilians and military specialists that conduct reconstruction projects or provide security for humanitarian and relief organizations. The PRT is one of the most important new developments in the transformation of organizational structures used in these types of operations. It provides a practical capability that capitalizes on interoperability and interagency integration, drawing on political, economic, civil, and military tools to achieve significant effects. The PRT possesses particularly attractive characteristics for NATO and its Partners: it is a small, largely independent command that is focused in its operational scope, non-logistics intensive, modular, and mobile. These features make it a readily deployable capability for nations that might otherwise be unable to contribute to multilateral expeditionary efforts. As of September 2005, there were twenty-one PRTs operating in Afghanistan, with significant PfP national representation, including Austria, Finland, Sweden, and Albania.

Based in large part on the experiences of ISAF, the EAPC has defined a unique long-term transformational strategy that focuses on pre-emptive global intervention and establishing stability in troubled regions. This bold vision clearly has its foundation in U.S. initiatives, but there is a distinctly "NATO flavor" to its pragmatism in identifying and addressing capability requirements, its focus on multi-national interdependence, and its emphasis on cooperatively integrating the military and other instruments of power to achieve holistic effects.

The NATO Response Force (NRF) provides "an integrated and fully interoperable sea, land, and air capability, under one command, wherever the North Atlantic Council requires, to prevent conflict or threat from escalating into a wider dispute." ${ }^{, 4}$ The NRF is envisaged as "a highly trained and technologically advanced operational military force" that is "ideally suited to identify new capabilities and concepts through lessons learned and serve as a test-bed for their analysis." ${ }^{, 2}$ NRF emphasizes full-spectrum utility, rapid deployability, exploitation of overarching technology, and joint and multi-

40 Jeffrey Simon, "Partnership for Peace: Charting a Course for a New Era"; available at http://usinfo.state.gov/journals/itps/0604/ijpe/simon.htm. PFP partners Finland, Sweden, and Austria; MAP-member Albania; and NATO invitees Romania and Bulgaria participated in ISAF.

41 “The NATO Response Force (NRF)," available at www.nato.int/shape/issues/shape_nrf/ 030820.htm.

42 General Lance L. Smith, "Understanding NATO Military Transformation," (ACT Multimedia Library, Norfolk, 2006), 16, http:/www.act.nato.int/multimedia/facts/UNMT\%20Booklet $\% 20$ English\%20Version.pdf. 
national interoperability as its essential operational capabilities. Although not fully fielded, the NATO Response Force has already made meaningful contributions to multi-lateral operations across the globe, from disaster relief following the 2005 Pakistan earthquakes and Hurricane Katrina, to a supporting role in Afghanistan's stability operations.

Significantly, many of the capabilities that were deployed were drawn from places other than the traditional combat-oriented toolbox, including life-support equipment, search and rescue teams, light and heavy engineering companies, and forensic specialists. ${ }^{43}$ Most recently, NATO provided strategic airlift to the African Union mission in Darfur, with a more expanded European role in UN-led African peacekeeping operations currently under consideration. The inclusive, geo-politically sensitive, and operationally diverse make-up of the NRF heightens its legitimacy and relevance in peacekeeping and humanitarian assistance operations where religious and ethnic strife are the primary destabilizing influences.

\section{The Role of Education: A Capabilities Development Process Enabler}

The Alliance has aspired to the ambitious objective of building forces that are agile, joint, and expeditionary in nature. The need is clear, but a common understanding of the mechanism for achieving these goals remains elusive. Concept development and experimentation (CD\&E) is a structured approach in which new and innovative ideas are explored, attempted, and evaluated through experimentation to produce capabilities that can be effectively employed on tomorrow's battlefield. CD\&E is an integral component of the capabilities development process that at present has been only partially incorporated. NATO would benefit from a coherent and collaborative education program that explains CD\&E in relation to the capabilities development process. Partners would additionally find value in an educational approach that relates NATO CD\&E to the development of Partnership Goals that meet PAP-DIB objectives.

Military leaders involved in national and collective transformation initiatives must have a basic understanding of the elements of the CD\&E process. CD\&E is the primary means within the capabilities development process to identify possible solutions for capability gaps. Leaders deserve targeted education in CD\&E that empowers them to formulate innovative ideas and approaches, conduct valid field experiments under realistic circumstances, assess the results, and provide cogent feedback to create viable solutions.

This novel approach to education begins with concept development. Traditional professional military education is often based on the application of doctrine. Doctrine encompasses already-mature capabilities that are employed to combat the threats of today. Concepts, on the other hand, are dynamic hypotheses that consider how things

43 SHAPE, "NATO's First Shipment of Relief Supplies Set to Move" (10 September 2005); available at www.nato.int/shape/news/2005/09/050910a.htm. 
might be done in the future to address potential security challenges. ${ }^{44}$ Often, these forward-looking concepts cannot be derived from existing doctrine or traditional educational approaches. Concept development thrives in educational venues that encourage collaboration and the free exchange of ideas, and that feature a community of participants with diverse experiences and backgrounds. Effective educational approaches will expose new concepts with varying degrees of maturity, provide opportunities for examining and vetting these concepts, and offer scenarios to explore their potential application to identified needs. ${ }^{45}$ This methodology will help future planners to form creative hypotheses that can be applied to future security challenges, and to critically examine new ideas for potential development. Applied properly, concept development provides justification for changes in doctrine based on exhaustive research and experimentation.

Training exercises and operational experience play an equally vital role in education, since these are the environmental conditions for experimentation and lessons learned. The experimentation phase of the CD\&E process is where concepts are converted into capabilities. This is a daunting task, as capabilities development is usually demand-driven. New concepts and identified capabilities needs are frequently derived from lessons learned in the field ${ }^{46}$ often, these experiences require immediate attention. In these situations, the experimentation phase is condensed considerably, and often conducted under less than ideal conditions. U.S. Navy Captain Steve Litwiller, ACT, Operational Concept Development Branch head, eloquently expressed this dilemma at the 2004 CD\&E conference: "As we're developing a new concept, commanders are already demanding the capabilities. We're forced to move out of the vac-

44 Defense Science Board 2005 Summer Study on Transformation: A Progress Assessment, Vol. II: Supporting Reports (April 2006), 117-120, http://www.acq.osd.mil/dsb/reports/200604-DSB_SS_Transformation_Report_Vol_2.pdf.

45 Jeffrey J. Becker, “Joint Concept Development at Joint Forces Command," Military Review 84:5 (July-August 2004); available at http://usacac.leavenworth.army.mil/CAC/milreview/ download/English/JulAug04/becker.pdf. One of the most poignant examples of the conduct of battlefield CD\&E is the transformation of field artillery into an indirect fire asset during the Civil War. Sgt. Milton Wylie Humphreys first field-tested this concept during the Civil War battle of Fayetteville. In his memoirs, Military Operations in Fayette County, West Virginia, 1861-1863 (Fayetteville, WV: Privately Issued by Charles A. Goddard, 1931), Humphreys gave the following account: "The term 'indirect fire' is firing upon a point or place (A) from a point (B) which is not visible to people at (A). It is necessary, of course, that the trajectory or path of the projectile should pass above the top of the 'mask' or intervening object. At Fayetteville, May 19 and 20, 1863, the writer used a grove as a mask, but at Winchester, Va., Sept. 19, 1864, he successfully used a low hill. I claim no credit for the 'invention'; the thing is so obvious. In fact, if I invented it, I did not do it at Fayetteville, but in my day-dreams when I was about 8 years old." 
uum of the labs and research within the give-and-take of operational environments. The world is our laboratory." 47

These fluid environmental conditions place much of the responsibility for operational experimentation in the hands of military leaders, as prototype capabilities are rapidly fielded in response to emerging threats. The primary difficulty in operational experimentation is meeting the requirement of scientific rigor. The correlation of actions and results is not causal. Validity (the ability to detect change and identify and isolate its cause) is a necessary prerequisite in field experiments to prove whether the tested capability causes the desired outcome. ${ }^{48}$ Military commanders are all too cognizant of the internal shortfall in much-needed experimentation expertise, and already employ senior concept developers and senior mentors from the transformation commands to interpret and evaluate the results of field experiments and training exercises. ${ }^{49}$ These efforts should now be coupled with a commitment to provide military leaders in the field with targeted education in transformation principles. Education of these future planners and policy makers early in their careers will encourage the evolution of political and military cultures that appreciate the importance of investment in transformation.

\section{Education and a Unified Approach to Transformation}

The JFCOM/ACT partnership appears firmly committed to comprehensive education and training in the field of transformation, both within its own organizations and throughout the EAPC. Since neither is an academic institution, the real responsibility for the delivery of relevant educational products for transformation falls upon U.S., NATO, and PfP education and training facilities. ACT serves as the hub that connects

${ }^{47}$ Capt. Litwiller set the stage for a lively exchange of ideas for how to "bridge the gap" between concept and capability in his opening remarks at the $2004 \mathrm{CD} \& \mathrm{E}$ conference in Calgary, Canada. Throughout the conference presentations, education and skill development of military officers was a resounding theme. Canada's liaison to US JFCOM, Lt.Col. Tony Battista, visualized these officers as "experimental directors" who battle-tested prototypes and newly developed capabilities in the field, then provided invaluable feedback and lessonslearned for vetting future concepts. Conference presentations are available at www.act.nato.int/organization/transformation/cde04post.htm. George Hodermarsky, "Introduction to Operational Experimentation," presented at the 2005 ACT/PfP CD\&E Workshop, Zagreb, Croatia (8-10 February 2005); available at www.act.nato.int/events/seminars/05cdeconfpost.htm.

This reflects an important cultural shift within the NATO military leadership, in which field commanders have embraced mentorship and partnership in exercises such as Urgent Quest 05, Allied Warrior 04, and the Joint Warrior Interoperability Demonstration 04, as highlighted in the 2004 CD\&E brief from ACT's Operational Experimentation branch head, Capt. Larry Gordon (available at http://www.act.nato.int/organization/transformation/ cde04post.htm). 
the transformation commands to the institutions that are responsible for the development of "cognitive" capabilities, as illustrated below: ${ }^{50}$

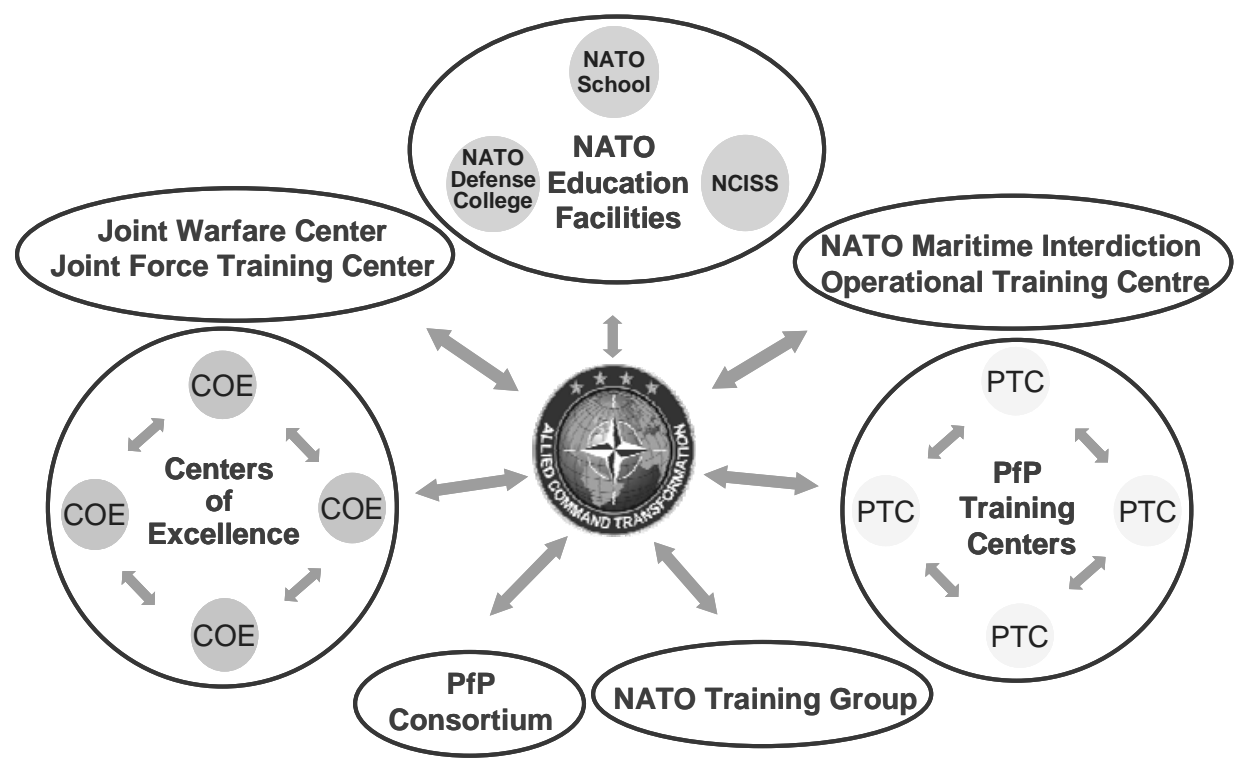

\section{Partnerships in Education}

The aforementioned International Defense Transformation (IDT) seminar is a prime example of this ACT/JFCOM partnership with the PfP training centers (in this case the Naval Postgraduate School) for the delivery of relevant educational products. The IDT seminar discusses revolutionary methods to improve command and control, fire, maneuver, and logistics in coalition and interagency operations across the spectrum of conflict through concept development, technology demonstrations, and field experiments. The key objectives of the seminar are to familiarize participants with:

- Capabilities-based approach for the future security environment

- Network-enabled capability and effects-based approach to operations

- Transformation elements: technology, organization, process, personnel

- Concept development and experimentation

50 This diagram is from BG Gundars Abols' brief "Individual Education and Training," which he presented at the 2006 PfP Transformation Conference (Skopje, March 2006). It illustrates ACT's role as the "Hub of Transformation" that links the NATO/PfP Education and Training Network (NPETN). BG Abols is ACT's Deputy Assistant Chief of Staff for Joint Education and Training (JET). 
The IDT seminar delivery method combines informational presentations and case studies with practical group exercises. The learning approach for IDT is based on the notion that cognitive capabilities are best developed by establishing a transformational frame of reference and then applying practical problem-solving methodologies to validate and refine transformation objectives. Academic lectures by internationally recognized professors and senior staff members on transformational principles, objectives areas, and best practices provide a theoretical foundation for participant discussion. The use of scenario-based practical exercises in an interactive group environment allows participants to consider their diverse viewpoints and negotiate unified transformation goals. The scenario for the exercise represents the realistic range of regional and transnational threats facing nations today. Participants develop a provisional national strategy for responding to principal threats, utilizing a capabilities-based defense planning methodology that considers what types of deployable and sustainable capabilities are required to contribute in multinational and interagency crisis response missions, both in the region and deployed abroad.

IDT participants include global civilian and military defense planners and policy makers that contribute a wide variety of real-world perspectives, issues, and experiences. Throughout the IDT seminar, these participants are introduced to relevant examples of attainable, feasible, and practical transformation prototypes, such as "Hastily Formed Networks," "Multi-national Interagency Group," "Coalition Combat Identification," and "Non-Lethal Weapons." Through the practical exercises, representatives from Partner nations have an opportunity to consider which type of prototype capabilities might be applicable in addressing their own Partnership Goals. Also of special importance for Partners, the IDT interaction with respected transformational professionals provides valuable insights on how the dimensions of CD\&E relate to the exploration, testing, and fielding of relevant PAP-DIB objective capabilities through the capabilities development process.

The IDT seminar program connects participants and subject-matter experts on a long-term basis through a Web-based collaborative continuous learning environment. This community of interest can continue to share transformational perspectives by email and engage in advanced distributed learning (ADL) activities. The Naval Postgraduate School-hosted website produces post-seminar "enrichment" modules in interdisciplinary subjects that address the varied elements of transformation, from explaining new planning methodologies to exploring the challenges of interagency integration. $^{51}$ The dynamic, collaborative IDT seminar venue enables learners to develop a core understanding of models, roles, and responsibilities for transformation. These are the cognitive capabilities that will inspire and shape national transformation agendas.

51 To date, there are four enrichment modules available on the International Defense Transformation Community Page in the Naval Postgraduate School Blackboard learning system: Crisis Action Planning, Interagency Integration, Task Lists Development, and Capabilities Management. For more information, or to access these modules, visit the Center for Civil-Military Relations website: www.ccmr.org/public/spd.cfm/spi/idt. 


\section{Conclusion}

The global security environment is rife with a host of uncertain and constantly evolving challenges. Unilateral reactive response and threat-based territorial defense are obsolete strategies for addressing asymmetric threats. Global partners must undergo a unified, interdependent, and forward-thinking transformation. It is ineffective and prohibitively expensive to continue developing capabilities that aspire primarily to overwhelming technological superiority and combat power in future operations. Planners and policy makers need to adapt an effects-based approach that utilizes all instruments of power to combat global threats. Through joint concept development and experimentation, alliances and coalitions can develop integrated capabilities that holistically engage collective challenges across the spectrum of conflict.

Effects-based approaches to operations, the capabilities development process, concept development and experimentation, and other transformational principles are revolutionary and dynamic approaches that require continuous and exhaustive evaluation and revision. These concepts are increasingly incorporated into national, joint, and collective strategic policy and doctrine,${ }^{52}$ but they are still not firmly institutionalized in international political and military cultural mindsets. A unified focus on education is the key to instilling an understanding and appreciation of transformational principles in future civilian and military leaders. Ideally, these future leaders will collaborate in a vibrant transformation community of interest that possesses the capability and ambition to effect transformation. Educational delivery methods should promote collaborative exchanges of ideas, link the transformation commands with academia and operational counterparts in the field, and actively engage participants in realistic scenarios that encourage practical application. This educational approach will endow future leaders with the skills and functional understanding necessary to translate core transformational concepts into operational capabilities that can be assessed and refined through continuous experimentation. For Partnership for Peace nations, this transformational mindset will enable the accomplishment of Partnership Goals that achieve PAP-DIB objective capabilities.

${ }^{52}$ See the recently released Quadrennial Defense Review Report (Washington, D.C.: Department of Defense, 6 February 2006), available at www.defenselink.mil/qdr/; and NATO's Strategic Vision: The Military Challenge (Brussels: NATO, August 2004); available at www.act.nato.int/organization/transformation/docs/stratvis0804.pdf. Both documents are current examples of strategic policy that focuses heavily on prescriptive transformation initiatives to address the evolving global security environment. 
THE QUARTERLY JOURNAL

\section{Bibliography}

Akçapar, Burak. "PfP Training Centres: Improving training and education in the Partnership for Peace." NATO Review 47:3 (1999).

Becker, Jeffrey J.. "Joint Concept Development at Joint Forces Command." Military Review 85, no. 4 (2004).

Borawski, John, and Thomas-Durell Young. NATO after 2000: The Future of the Euro-Atlantic Alliance. Westport, CT: Praeger, 2001.

Simon, Jeffrey. "Partnership for Peace: Charting a Course for a New Era." Strategic Forum, no. 206 (2004).

Smith, General Lance L.. Understanding NATO Military Transformation. ACT Multimedia Library, Norfolk, VA, 2006. 